\title{
Effect of nutritional iron deficiency on acute and chronic inflammation
}

\author{
F J ANDREWS, ${ }^{1}$ C J MORRIS, ${ }^{1}$ E J LEWIS, ${ }^{2}$ AND D R BLAKE
}

From the ${ }^{1}$ Department of Rheumatology, The Medical School, University of Birmingham; and the ${ }^{2}$ Department of Biology, Roche Products Ltd, Welwyn Garden City, Herts

SUMmARY Mild nutritional iron deficiency significantly reduced the severity of adjuvant induced joint inflammation assessed by histology, microfocal radiography, and subjective scoring. Other indices of adjuvant induced inflammation, such as increased levels of serum acute phase reactants, characteristic pathological changes in the inguinal lymph nodes, and granuloma formation at the site of adjuvant injection, were not different from those of control animals. The level of iron deficiency used did not affect the acute inflammatory response to a range of irritants and was not sufficient to suppress immune function. Both the hypersensitivity reaction to oxazalone and lymphocyte tritiated thymidine incorporation were normal. These observations support the view that iron has a selective influence on joint mediated inflammation.

The potential importance of iron in rheumatoid disease is well recorded. ${ }^{1}$ Any sustained inflammatory reaction causes changes in iron metabolism, with a drop in serum iron and a redistribution of iron to the activated reticuloendothelial system including, in rheumatoid disease, the inflamed synovium. Muirden and Senator suggested that this synovial iron deposition contributed to the joint inflammation, ${ }^{2}$ and Blake et al found that high levels of synovial iron anticipated a poor prognosis in early rheumatoid patients. ${ }^{3}$ Treatment of the anaemia associated with rheumatoid disease with intravenous iron dextran and with oral iron has been shown to exacerbate joint symptoms. ${ }^{45}$

Removal of deposited iron may, therefore, be expected to reduce inflammation and in support of this the iron chelator desferrioxamine has antiinflammatory properties in a variety of models of inflammation. ${ }^{7}$ Recently we have shown that desferrioxamine treatment also significantly suppresses adjuvant disease in the rat. ${ }^{8}$ Adjuvant disease is a well recorded model, in which there is a local inflammatory response at the site of injection, ${ }^{9}$ generalised focal arthritis, synovitis and tendonitis ${ }^{10}$ accompanied by systemic lesions affecting the eyes, skin, urogenital and gastrointestinal systems. ${ }^{11}$ Characteristic pathological changes occur in the

Accepted for publication 12 April 1987.

Correspondence to Dr D R Blake, Department of Rheumatology, The Medical School, University of Birmingham, Birmingham B15 2TJ. lymph nodes draining the injection site,${ }^{12}$ and there is an increase in serum acute phase reactants ${ }^{13}$ and peripheral blood neutrophils. ${ }^{14}$ The inflamed synovium has also been shown to contain iron deposits. ${ }^{15}$ Desferrioxamine treatment appeared to reduce the joint symptoms of adjuvant disease specifically without affecting the systemic and local sequelae. Desferrioxamine, however, will chelate a range of other metals. ${ }^{16}$ In view of this we have extended our studies to look at the effect of mild nutritional iron deficiency on adjuvant disease and on models of acute inflammation not involving the joint. As iron deficiency may be associated with immune suppression we have also examined the effect of nutritional iron deficiency on lymphocyte proliferation and cell mediated immunity.

\section{Materials and methods}

Postweaned, male Wistar rats were obtained from Bantin and Kingman (Hull, UK). The test rats for each experiment were fed a commercial iron deficient diet (Volac, Royston, UK) with an iron concentration of $20 \mathrm{ppm}$. The control rats were maintained on the same diet plus iron supplementation in the form of ferrous sulphate to give a total iron concentration of $120 \mathrm{ppm}$. This corresponds with the recommended iron concentration found in commercial rat and mouse feed (Heygate \& Sons, Northampton, UK). Both test and control rats in each experiment received food and triple distilled water freely. 
All rats were weighed at weekly intervals. After five weeks measurement of haemoglobin levels using a cyanomethaemoglobin technique (Sigma, USA) confirmed that a mild iron deficiency had been established in the test rats. The rats were then divided into groups of 12 iron deficient (test) and 12 iron supplemented (control) rats in each experiment. At the end of each experiment haemoglobin levels were reassessed and samples of liver were removed for measurement of hepatic iron, copper, and zinc concentrations by atomic absorption.

CHRONIC INFLAMMATION

Adjuvant disease was induced on day 0 in iron deficient and control rats by the method of Kaibara et al. ${ }^{17}$ All rats received a single intradermal injection in the base of the tail of $0.1 \mathrm{ml}$ of a $10 \mathrm{~g} / \mathrm{l}$ solution of Mycobacterium butyricum (Difco, Surrey, UK) in liquid paraffin oil. Joint inflammation was assessed by an established method based on the foot scoring system first described by Currey and Ziff. ${ }^{18} \mathrm{~A}$ subjective score of $0-4$ was allocated to each hind foot depending upon the extent of inflammation, with a maximum score of eight per rat. Scoring was as follows: $0=$ no inflammation, $1=$ redness and swelling of the foot, $2=$ swelling of the foot such that the tendons were no longer visible, 3 = swelling extending to the ankle joint, and $4=$ gross inflammation and deformities of the ankle joint. To eliminate bias scoring was carried out by two independent observers, one of whom had no knowledge of the treatments used in this experiment (see statistics).

All rats were killed on day 21 , and the hind ankle joints were removed for histology and radiography. Joint tissue was decalcified and processed by a standard histological procedure. Paraffin sections (5 $\mu \mathrm{m})$ were cut and stained with haematoxylin and eosin. Sections from each rat joint were assessed independently by the authors and by Dr G Kondratowicz (Department of Pathology, University of Birmingham). Joints were $x$ rayed using microfocal radiography. The $x$ ray system used in this work comprised a demountable $x$ ray unit, an $\mathrm{X}-\mathrm{Y}$ positioning frame, and a Marconi image intensifier and monitor. The special $25 \mu \mathrm{m}$ microfocal $x$ ray set had an effective resolution of $>20$ line pairs $/ \mathrm{mm}$. Radiographs of each rat ankle joint were obtained at a magnification of $\times 10$ using standard $x$ ray cassettes positioned in front of the image intensifier. Exposures were $40 \mathrm{kV}$ (0.4 MA). Radiographs were assessed independently by the authors and by Dr N Evans (Selly Oak Hospital, Birmingham).

The primary inflammatory response at the base of the tail was assessed by measuring the diameter of the lesion. Serum acute phase reactants were measured using a COBAS BI0 centrifugal microanalyser, and levels were compared with those of six normal rats of the same strain, sex, and age. Differential leucocyte counts were made of fresh blood smears removed from each rat. The inguinal lymph nodes were removed from each rat and processed by a standard histological procedure. The hyperplastic response of the lymph node to adjuvant was assessed semiquantitatively by measuring the maximum diameter of the nodes and determining $\vec{O}$ the presence or absence of secondary follicles, paracortical hyperplasia, sinus histiocytosis, and dilatation and granulomata formation.

ACUTE IN F L AMMATION

\section{Carrageenan pleurisy}

Carrageenan pleurisy was induced in iron deficient of and control rats by the method of Velo et al. ${ }^{19}$ Rats $\mathcal{G}$ were killed and exudate collected at five hours after 을 induction of pleurisy.

\section{Urate pleurisy}

Pleurisy was induced using $0.2 \mathrm{ml}$ of a $1 \%$ suspension of sodium biurate in phosphate buffered saline $\underset{\complement}{\Phi}$ (PBS) following the above method.

\section{Pyrophosphate foot pad}

Foot pad oedema was induced using $0.2 \mathrm{ml}$ of a $1 \%$ suspension of calcium pyrophosphate in PBS injected into the left hind foot pad. Foot pad oedema was assessed by measuring the circumference of the inflamed left foot at $1,2,3,4$, and 24 hours postinjection and subtracting the value for the non-inflamed right foot.

\section{M M U NOLOGY}

\section{Oxazalone hypersensitivity}

Sensitisation and contact challenge with oxazalone $\frac{5}{7}$ was carried out by the method of Kishore et al.$^{20}$ Ear oedema was measured at 0,24 , and 48 hours postchallenge using a micrometer.

\section{Lymphocyte proliferation}

Both iron deficient and control cells were cultured in both iron deficient and control serum. Cultures N were carried out in sterile microplates in triplicate with $1.5 \times 10^{6}$ cells in $100 \mu \mathrm{l}$ RPMI containing $\tilde{D}$ $10 \%$ rat serum, $2 \mathrm{mM}$ glutamine, 100 units $/ \mathrm{ml}$ 出 penicillin, $100 \mu \mathrm{g} / \mathrm{ml}$ streptomycin or concanavalin A $9 \mu \mathrm{g} / \mathrm{ml}$ (Pharmacia, Sweden) orọ phytohaemagglutinin $280 \mu \mathrm{g} / \mathrm{ml}$ (Difco labs, USA).

The preparations were incubated for 66 뭉 hours at $37^{\circ} \mathrm{C}$ in a humidified atmosphere with $\stackrel{\vec{P}}{\overrightarrow{0}}$ $5 \% \mathrm{CO}_{2}$ and $95 \%$ air. After 48 hours of 
culture $5.6 \mathrm{kBq}$ of $\left[{ }^{3} \mathrm{H}\right]$ thymidine (Radiochemical Centre, Amersham, UK) was added to each well. Cells were harvested on filter mats using a multiple cell harvester (Skatron for Flow Laboratories). Incorporation of $\left[{ }^{3} \mathrm{H}\right]$ thymidine into lymphocyte DNA was measured in a liquid scintillation counter and expressed as counts/ minute.

\section{S T A T I S T I C S}

Analysis of parametric data was carried out with Student's $t$ test (ST) and is expressed as the mean (SD). Non-parametric data were analysed with the Mann-Whitney U test (MW). The difference between the two observers' foot scores was analysed with a Wilcoxon signed rank test.

\section{Results}

Mild nutritional iron deficiency did not appear to affect the rats general health adversely. Both groups of animals followed the same growth curve, and there was no significant difference in body weight.
Rats fed on the iron deficient diet had significantly reduced haemoglobin levels compared with the controls (115.7 (9.4) g/l $v 131.3(8.4) \mathrm{g} / \mathrm{l}, \mathrm{p}<0.01$ (ST)). Iron deficient rats had significantly reduced hepatic iron stores compared with controls $(35.7$ (7) $\mathrm{mg} / \mathrm{kg} v 186(41) \mathrm{mg} / \mathrm{kg}, \mathrm{p}<0.001$ (ST)). Hepatic copper and zinc levels were unaffected by the iron deficiency. (Copper levels-iron deficient $5.3(1.7)$ $\mathrm{mg} / \mathrm{kg}$, control $5.2(1.7) \mathrm{mg} / \mathrm{kg}$; zinc levels-iron deficient $28.3(8.9) \mathrm{mg} / \mathrm{kg}$, control $25.9(7.1) \mathrm{mg} / \mathrm{kg}$ (ST).)

\section{CHRONIC INFLAMMATION}

Initial signs of arthritis were noted from day 12 . From day 12 to 14 there was no significant difference in joint score between the iron deficient and control rats. By day 15 the control animals had developed an intense destructive polyarthritis, while joint inflammation in the iron deficient group was significantly reduced (Fig. 1). There was no significant difference between the scores of the two observers as assessed by the Wilcoxon signed rank test.

All the control rats had evidence of periarticular
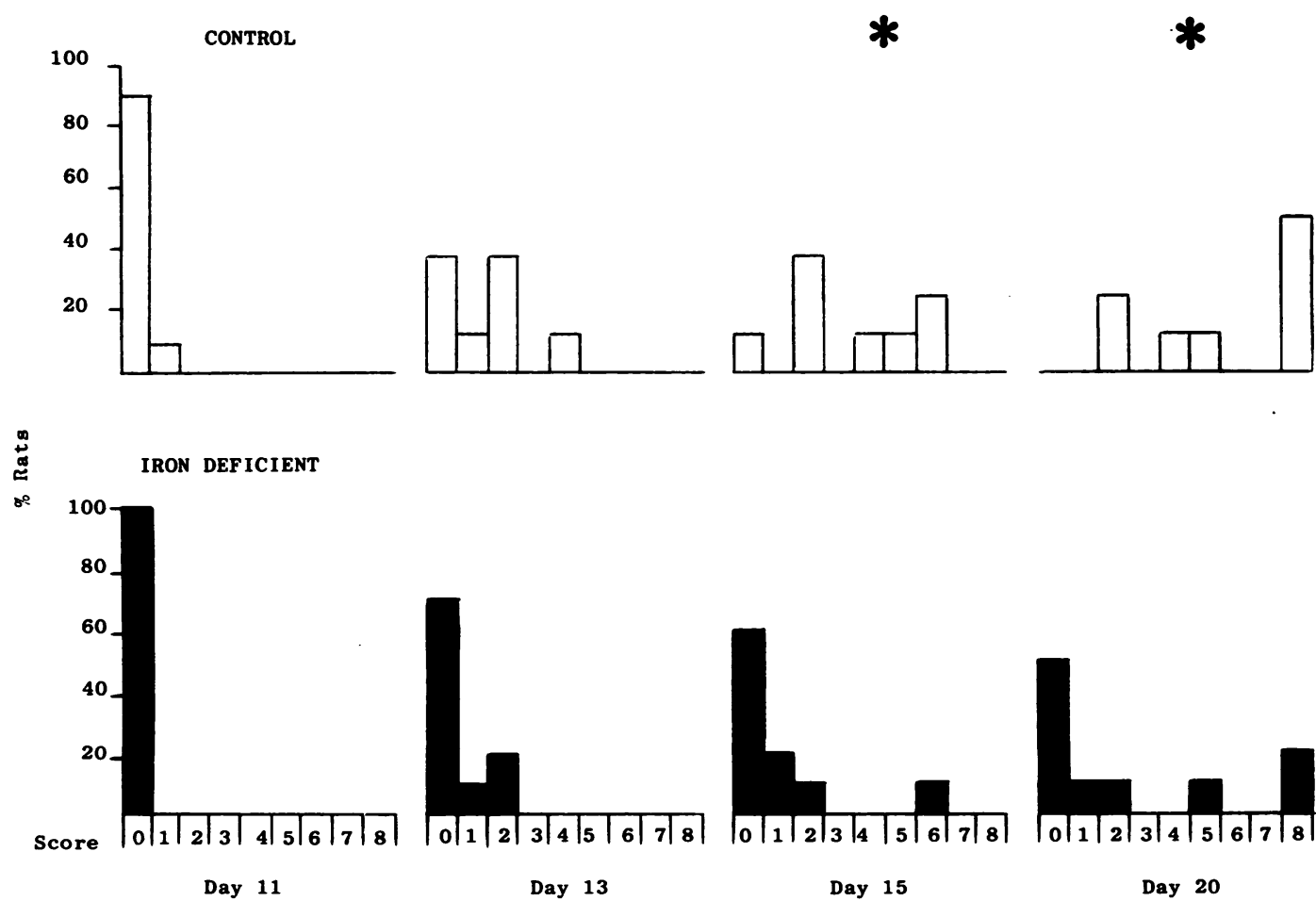

Days post injection

Fig. 1 Development of joint inflammation in iron deficient and control rats with adjuvant disease. Percentage of rats with a given foot score during the course of disease ( $n=12$ in each group, ${ }^{*} p<0.05$ (Mann-Whitney)). 
connective tissue inflammation with an infiltrate consisting mainly of polymorphs with a few lymphocytes, histiocytes, and mast cells. All of the sections showed synovitis, bursitis, infiltration of the synovium with polymorphs, and exudation into the synovial space. Half of the control animals had evidence of fibroblastic proliferation and granulation tissue formation with areas of bone resorption, osteoblastic proliferation, and disorganised new bone formation. In contrast, two iron deficient rats showed no signs of joint disease, and the inflammation observed in eight of the rats was restricted to a mild synovitis and periarticular connective tissue inflammation. Interestingly, the infiltrate consisted of a mixture of polymorphs and lymphocytes, the numbers of polymorphs being greatly reduced compared with those observed in the control sections. Only two animals had developed bone erosions.

These results were reflected in the microfocal radiographs, where all of the control rats had evidence of soft tissue swelling. Half of these animals had osteoporosis of the tibial head, and four rats had florid new bone formation and periostitis. Only two iron deficient rats showed any signs of bone changes and these were similar to those of the control animals.

Both iron deficient and control rats developed a primary inflammatory focus at the site of injection in the base of the tail. There was no significant difference in the diameter of the lesion (iron deficient $7.00(5.5) \mathrm{mm}$, control $4.67(3.57) \mathrm{mm}$ (ST)). Both iron deficient and control rats showed significant changes in serum acute phase reactants compared with rats of the same age, strain, and sex with no adjuvant disease. There was no significant

Table 1 Change in serum acute phase reactant as a result of adjuvant disease in iron deficient and control rats compared with rats with no disease

\begin{tabular}{|c|c|c|c|}
\hline Test & Iron deficient & Control & No adjuvant \\
\hline Iron $(\mu \mathrm{mol} / \mathrm{l})$ & $25 \cdot 1(3 \cdot 6)$ & $28 \cdot 8(6 \cdot 6)$ & $35 \cdot 1(5 \cdot 7)^{*}$ \\
\hline TIBC $(\mu \mathrm{mol} / \mathrm{l})$ & $108(10) \dagger$ & $97(6)$ & $95(6)^{* *}$ \\
\hline Haptoglobin (g/l) & $2 \cdot 34(0 \cdot 6)$ & $2 \cdot 19(0.8)$ & $0.47(0.17)^{*}$ \\
\hline $\begin{array}{l}\text { Caeruloplasmin } \\
\text { (mg/l) }\end{array}$ & $1033(194)$ & 892 (266) & $345(22)^{*}$ \\
\hline Albumin (g/l) & $26 \cdot 1(1 \cdot 8)$ & $25.9(2.0)$ & $31.9(1.2)^{*}$ \\
\hline $\begin{array}{c}\text { Cholesterol } \\
(\mathrm{mmol} / \mathrm{l})\end{array}$ & $1.5(0 \cdot 2)$ & $1 \cdot 7(0 \cdot 2)$ & $1.3(0.3)^{* * *}$ \\
\hline Seromucoid $(g / l)$ & $12 \cdot 7(5 \cdot 2)$ & $11 \cdot 5(6 \cdot 5)$ & $4.33(0.7)^{*}$ \\
\hline
\end{tabular}

Values are mean (SD).

Statistics-Student's $t$ test, $n=12$ in each group.

*Iron deficient compared with rats with no disease: ${ }^{*} p<0.001$, ${ }^{* *} \mathrm{p}<0 \cdot 1,{ }^{* * *} \mathrm{p}<0.05$.

†Iron deficient TIBC (total iron binding capacity) compared with control $\mathrm{p}<0.01$. difference between the two experimental groups except for total iron binding capacity (TIBC) (Table 1). Serum iron levels were reduced in control rats to $\overrightarrow{\overrightarrow{\vec{A}}}$ the level in the iron deficient rats as a result of $\stackrel{\vec{C}}{+}$ adjuvant disease. ${ }^{21}$ Both iron deficient and control? rats had a significantly higher percentage of neut $-\frac{\bar{\sigma}}{\bar{\rho}}$ rophils in the peripheral blood compared with rats $\frac{\bar{\sigma}}{\widetilde{\sigma}}$ with no adjuvant disease (iron deficient $50(8) \%$ 응 neutrophils, 46 (8)\% lymphocytes, control 53 (9)\% \% neutrophils, 42 (7)\% lymphocytes; normal rats 19 우 (6)\% neutrophils, 79 (5)\% lymphocytes, p $<0.001$. (ST)).

Inguinal lymph nodes from both iron deficient and control rats showed a similar response to the adjuvant. There were no significant differences in $\vec{\sigma}$ the maximum diameter of the nodes (iron deficient: $4.3(1.0) \mathrm{mm}$, control $4.0(0 \cdot 5) \mathrm{mm}(\mathrm{ST}))$, presence ${ }_{\infty}^{-}$ or absence of paracortical hyperplasia, sinus his- -5 tiocytosis and dilatation, or the proportion of nodeso in each group showing secondary follicle formation? (iron deficient $75 \%$, control $66 \%$ (MW)). The $z$ control rats, however, had significantly fewer granu-은 lomata in the lymph nodes $(25 \%$ controls, $66 \%$ iron deficient, $\mathrm{p}<0.005$ (MW)).

\section{ACUTE INFLAMMATION}

Carrageenan pleurisy

There was no significant difference in exudate volume (iron deficient $1.00(0.14) \mathrm{ml}$, control 0.99 $(0.09) \mathrm{ml}(\mathrm{ST}))$ or the exudate total leucocyte count (iron deficient $88.58(16) \times 10^{6} \mathrm{cells} / \mathrm{ml}$, control 83.960 (21) $\times 10^{6}$ cells $\left./ \mathrm{ml}(\mathrm{ST})\right)$.

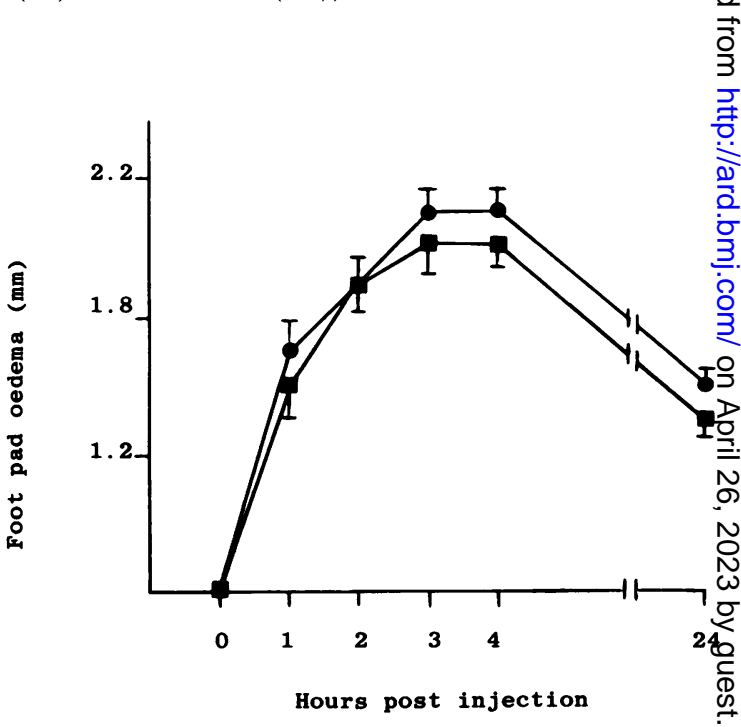

Fig. 2 Development of foot pad oedema after injection with calcium pyrophosphate crystals. Iron deficient, control. 
Table 2 Resting and mitogen stimulated ${ }^{3} \mathrm{H}$ incorporation measured in iron deficient (test) and control cells and serum

\begin{tabular}{lllll}
\hline Cells & Serum & $\begin{array}{l}\text { Resting } \\
(\text { cpm })\end{array}$ & $\begin{array}{l}\text { PHA 100 } \mu l \\
(\text { cpm })\end{array}$ & $\begin{array}{l}\text { PHA 50 } \mu l \\
(\text { cpm })\end{array}$ \\
\hline Test & Control & $52(7)$ & $28583(212)$ & $16534(3026)$ \\
Test & Test & $50(7)$ & $27705(1307)$ & $13793(2235)$ \\
Control & Control & $48(6)$ & $17522(1381)$ & $13742(482)$ \\
Control & Test & $40(10)$ & $17958(1225)$ & $12973(368)$ \\
\hline Cells & Serum & Resting & Con A $50 \mu l$ & \\
& & $(c p m)$ & $(c p m)$ & \\
\hline Test & Control & $60(6)$ & $17913(6379)$ & \\
Test & Test & $58(7)$ & $19644(2312)$ & \\
Control & Control & $37(5)$ & $14050(600)$ & \\
Control & Test & $45(2)$ & $14981(731)$ & \\
\hline
\end{tabular}

Values are mean (SD).

Con $\mathrm{A}=$ concanavalin $\mathrm{A}$; $\mathrm{PHA}=$ phytohaemagglutinin.

\section{Urate pleurisy}

There was no significant difference in the exudate volume (iron deficient $1.03(0.07) \mathrm{ml}$, control 1.00 $(0 \cdot 14) \mathrm{ml}(\mathrm{ST}))$ or the exudate total leucocyte count (iron deficient $80 \cdot 86(26) \times 10^{6}$ cells $/ \mathrm{ml}$, control 82.20 $(19) \times 10^{6}$ cells $\left./ \mathrm{ml}(\mathrm{ST})\right)$.

\section{Pyrophosphate foot pad}

Iron deficiency did not significantly affect the development of foot pad oedema induced by calcium pyrophosphate crystals (Fig. 2).

\section{M M U N O L O G Y}

\section{Oxazalone hypersensitivity}

There was no significant difference in ear oedema in response to challenge with oxazalone between iron deficient and control rats.

\section{Lymphocyte proliferation}

Iron deficiency did not significantly affect $\left[{ }^{3} \mathrm{H}\right]$ thymidine incorporation by resting and mitogen stimulated lymphocytes (Table 2 ).

\section{Discussion}

Nutritional iron deficiency has traditionally been described as detrimental to host defences against disease. In recent controversies a possible protective role against heart disease, ${ }^{22}$ cancer, ${ }^{23}$ and both bacterial and parasitic infections ${ }^{24}$ has been attributed to it.

Our results suggest a selective beneficial effect of nutritional iron deficiency in reducing joint inflammation in the adjuvant model. Iron deficiency did not affect the development of the primary inflammatory focus at the site of injection, however, nor the systemic complications characteristic of adjuvant disease, such as raised acute phase reactants, ${ }^{13}$ altered peripheral blood lymphocyte, neutrophil ratios, ${ }^{14}$ and inguinal lymph node hyperplasia. ${ }^{12}$ The same levels of iron deficiency had no influence on the acute inflammatory response to carrageenan, sodium biurate, or calcium pyrophosphate.

Nutritional iron deficiency has been associated with a suppression of immune function. ${ }^{25}$ Iron deficient patients are reported to have a decreased percentage of $\mathrm{T}$ lymphocytes,${ }^{26}$ impaired incorporation of $\left[{ }^{3} \mathrm{H}\right]$ thymidine by stimulated lymphocytes in culture, ${ }^{27}$ and a depressed delayed hypersensitivity response. ${ }^{28}$ Nutritionally iron deficient rats have been reported to have impaired humoral ${ }^{29}$ and cell mediated immunity. ${ }^{30}$ The lymphocyte abnormalities may result from defective DNA synthesis and cell proliferation due to a reduced activity of the iron containing enzyme ribonucleotide reductase. ${ }^{31}$ The modest level of iron deficiency produced in our experiments, however, did not affect the development of oxazalone hypersensitivity or lymphocyte $\left[{ }^{3} \mathrm{H}\right]$ thymidine incorporation.

Nutritional iron deficiency has been associated with abnormalities in neutrophil function, though phagocytic function may remain normal. ${ }^{32}$ Iron deficient neutrophils have been shown to be defective in the oxidative reduction of nitroblue tetrazolium dye by the superoxide radical, suggesting the activity of the iron containing enzyme NADPH oxidase is reduced.$^{33}$ In addition, the activity of myeloperoxidase, an important bactericidal system which contains iron, may also be adversely affected by iron deficiency. ${ }^{34}$

Iron is an important catalyst in the production of the most toxic oxygen radical $\mathrm{OH}^{*}$ from superoxide and hydrogen peroxide by the Fenton reaction.

$$
\begin{aligned}
2 \mathrm{O}_{2}^{-}+2 \mathrm{H}^{+} & \rightarrow \mathrm{H}_{2} \mathrm{O}_{2}+\mathrm{O}_{2} \\
\mathrm{Fe}^{++}+\mathrm{H}_{2} \mathrm{O}_{2} & \rightarrow \mathrm{Fe}^{3+}+\mathrm{OH}^{-}+\mathrm{OH}^{-}
\end{aligned}
$$

During inflammation it is thought that oxygen radicals produced by stimulated phagocytic cells contribute to tissue damage by inducing lipid peroxidation. ${ }^{35}$ There is evidence that such a process may contribute to joint inflammation as lipid peroxidation products have been found in synovial fluid both from rheumatoid patients and rats with adjuvant arthritis. ${ }^{36}{ }^{37}$ In both diseases iron deposits occur in the inflamed synovium, ${ }^{2}{ }^{15}$ and in rheumatoid synovial fluid iron is present in a form capable of catalysing the Fenton reaction. ${ }^{38}$ Inhibitors of the superoxide radical are reported to significantly reduce joint inflammation and the production of lipid peroxidation products in adjuvant disease. ${ }^{39}$ The presence of stimulated phagocytic cells in the 
inflamed area provides one mechanism for the generation of oxygen radical damage. It is of interest that there were fewer neutrophils in the joint tissue of iron deficient rats in our experiments than in the controls, though the percentage of neutrophils in the circulation remained high. This is unlikely to be related to a straightforward reduction in neutrophil recruitment in iron deficiency as there was no significant reduction in neutrophil counts in the pleural exudate from iron deficient rats.

Although oxygen radical production during inflammation is by no means specific to the joint, there is evidence that the joint provides a unique environment that may account for the specificity of our results. We have previously shown that exercise of the inflamed rheumatoid knee joint results in significant intra-articular pressure increases and decreased synovial fluid oxygen tension. ${ }^{40}$ When the joint was rested the intra-articular pressure returned to normal resting levels but the synovial fluid oxygen tension increased. Synovial fluid fluorescent IgG levels (thought to be formed in vivo by free radical mediated damage to the $\operatorname{IgG}$ molecule ${ }^{41}$ ) varied with those of the oxygen tension.

McCord was the first to show that ischaemia followed by reperfusion of the tissues resulted in metabolic changes during the ischaemic period leading to the production of oxygen free radicals during reperfusion. ${ }^{42}$ We have postulated that such a process occurs in the inflamed joint. ${ }^{43}$ Ischaemia results in the delocalisation of cellular protein bound iron to smaller chemical species capable of catalysing free radical mediated lipid peroxidation. ${ }^{44}$ Iron chelation using desferrioxamine has been shown to significantly reduce the tissue damage following cardiac arrest. ${ }^{45}$ It is possible that nutritional iron deficiency specifically reduces joint inflammation by reducing the available iron required for oxygen free radical production. Further support for the ischaemia/reperfusion hypothesis comes from the observation that bed rest or splinting of inflamed joints is clinically beneficial and that immobilisation of the limbs by sciatic denervation significantly reduced the severity of joint symptoms in adjuvant disease. ${ }^{46}$

We have shown that nutritional iron deficiency has a beneficial effect in reducing joint inflammation in the adjuvant model without affecting the systemic components of the disease or the models of acute inflammation. This observation suggests an apparently selective influence of iron on joint mediated inflammation.

DRB and CJM are in receipt of grants from the West Midlands Regional Health Authority, the British Technology Group (UK), and the Arthritis and Rheumatism Council (UK). We are grateful for the assistance of Mr J Henderson (Radiation, Physics, $\square$ Birmingham University) and Dr N Evans (Selly Oak Hospital, Birmingham) with the microfocal radiography, Dr G Kondratowicz $\Rightarrow$ (Department of Pathology, University of Birmingham) with the histology, and Mr B Davies (County analyst, Birmingham) for the atomic absorption. Professor P Dieppe (Bristol Royal Infirmary) kindly donated the urate and pyrophosphate crystals. We are also grateful for the secretarial assistance of Mrs J Jones.

\section{References}

1 Blake D R, Hall N D, Bacon P A, Dieppe P A, Halliwell B, Gutteridge J M C. The importance or iron in rheumatoid. disease. Lancet 1981; ii: 1141-4.

2 Muirden K D, Senator G B. Iron in the synovial membrane in rheumatoid arthritis and other joint diseases. Ann Rheum Dis 1968; 27: 38-47.

3 Blake D R, Gallagher P J, Potter A R, Bell M J, Bacon P A. The effect of synovial iron on the progression of rheumatoid? disease. Arthritis Rheum 1985; 27: 495-501.

4 Blake D R, Lunec J, Ahern M, Ring E F J, Bradfield J, $\infty$ Gutteridge J M C. Effect of intravenous iron dextran on rheumatoid synovitis. Ann Rheum Dis 1985; 44: 183-8.

5 Blake D R, Bacon P A. Effect of oral iron on rheumatoid arthritis. Lancet 1982; i: 623.

6 Blake D R, Hall N D, Bacon P A, Dieppe P A, Halliwell B, Z Gutteridge J M C. Effect of a specific iron chelating agent on? animal models of inflammation. Ann Rheum Dis 1983; 42:ه 89-93.

7 Sedgwick A D, Blake D R, Winwood P, Moore A R, Al Duaij吕 A, Willoughby D A. Studies into the effects of the iron chelator desferrioxamine on the inflammatory process. Eur $J$ Rheumpo Inflamm 1984; 7: 87-94.

8 Andrews F J, Morris C J, Kondratowicz G, Blake D R. Eftề of iron chelation on inflammatory joint disease. Ann Rheum $\overline{\text { Bis }}$ 1987; 46: 327-33.

9 Pearson C M, Wood F D. Studies of polyarthritis and other lesions induced in rats by injection of mycobacterial adjuvant. I.ఎ General clinical and pathological characteristics and some $\frac{0}{\square}$ modifying factors. Arthritis Rheum 1959; 2: 440-59.

10 Pearson C M. Development of arthritis, periarthritis and periostitis in rats given adjuvant. Proc Soc Exp Biol Med 1956; 윽 91: 95-101.

11 Pearson C M, Waksman B H, Sharp J T. Studies of arthritis and other lesions induced in rats by injection of mycobacterial adjuvant. V. Changes affecting the skin and mucous membranes. J Exp Med 1961; 113: 485-509.

12 Glenn E M, Gray J. Adjuvant induced polyarthritis in rats: biologic and histologic background. Am J Vet Res 1964; 26:3. 1180-94.

13 Gralla E J. Wiseman E H. The adjuvant arthritic rat: inflammatory parameters during development and regression of gross lesions. Proc Soc Exp Biol Med 1968; 128: 493-5.

14 Glenn E M, Bowman B J, Rohioff N A, Seeley R J. A major contributory cause of arthritis in adjuvant inoculated rats $=\frac{D}{O}$ granulocytes. Agents Actions 1977; 7: 265-82.

15 Muirden K D, Peace G. Light and electron microscope studies in carrageenan adjuvant and tuberculin induced arthritis. Ann Rheum Dis 1969; 28: 392-401.

16 Hider R C. Siderophore mediated absorption of iron. Structure and Bonding 1984; 58: 26-87.

17 Kaibara N, Hotokebuchi B, Takagishi K, et al. Pathogenico differences between collagen arthritis and adjuvant arthritis. Exp Med 1984; 159: 1388-96.

18 Currey H L F, Ziff M. Suppression of adjuvant disease in the rat by heterologous anti lymphocyte globulin. J Exp Med 1968; 127: 185-203.

19 Velo G P, Dunn C J, Giroud J P, Timsit J, Willoughby D A Distribution of prostaglandins in the inflammatory exudate. Pathol 1973; 111: 149-58. 
20 Kishore V, Latman N, Roberts D W, Barnett J B, Sorenson J R J. Effect of nutritional copper deficiency on adjuvant arthritis and immunocompetence in the rat. Agents Actions 1984; 14: 274-82.

21 Mikolajew M, Kuratowska Z, Kossakowska M, Placheka M, Kopec M. Haematological changes in adjuvant disease in the rat. II. Iron metabolism and ${ }^{51} \mathrm{Cr}$ erythrocyte survival. Ann Rheum Dis 1969; 28: 172-9.

22 Shaper A G, Jones K W. Serum cholesterol, diet and coronary heart disease in Africans and Asians in Uganda. Lancet 1959; ii: 534-7.

23 Martin W. Do we get too much iron? Med Hypotheses 1984; 13: 119-21.

24 Maswe A E J. Infections in iron deficiency and other types of anaemia in the tropics. Lancet 1974; ii: 314-7.

25 Dallman P R, Beutter E, Finch C A. Effects of iron deficiency exclusive of anaemia. Br J Haematol 1978; 40: 179-84.

26 MacDougall L G, Anderson R, McNab G M, Katz J. The immune response in iron deficient children: impaired cellular defence mechanisms with altered humoral components. $J$ Pediatr 1975; 86: 833-43.

27 Joynson D H M, Jacobs A, Murray-Walker D, Dolby A E. Defect of cell mediated immunity in patients with iron deficiency anaemia. Lancet 1972; ii: 1058-9.

28 Swarup-Mitra S, Sinha A K. Cell mediated immunity in nutritional anaemia. Indian J Med Res 1984; 79: 354-62.

29 Kochanowski B A. Sherman A R. Decreased antibody formation in iron deficient rat pups. Am J Clin Nutr 1985; 41: 278-84.

30 Kochanowski B A. Sherman A R. Cellular growth in iron deficient rats. J Nutr 1985; 115: 279-87.

31 Hoffbrand A V. Ganeshaguru K, Hooton J W L, Tattersall M H N. Effect of iron deficiency and desferrioxamine on DNA synthesis in human cells. Br J Haematol 1976; 33: 517-26.

32 Chandra R K. Reduced bactericidal capacity of polymorphs in iron deficiency. Arch Dis Child 1973; 48: 864-6.

33 Moore L L, Humbert J R. Neutrophil bacterial dysfunction towards oxidant radical-sensitive micro-organisms during experimental iron deficiency. Pediatr Res 1984; 18: 684-6.

34 Mackler B, Person R, Ochs H, Finch C A. Iron deficiency in the rat: ettects on neutrophil activation and metabolism. Pediatr Res 1984; 18: 549-51.

35 Halliwell B, Gutteridge J M C. Oxygen toxicity, oxygen radicals, transition metals and disease. Biochem $J$ 1984; 219: 1-14.

36 Lunec J, Halloran S P, White A G, Dormandy T L. Free radical oxidation products in serum and synovial fluid in rheumatoid arthritis. J Rheumatol 1981; 8: 233-45.

37 Yoshikawa $\mathrm{T}$, Tanaka $\mathrm{H}$, Kondo $\mathrm{M}$. Lipid peroxidation in rat adjuvant arthritis and its inhibition by indomethacin. $J$ Appl Biochem 1983; 5: 382-7.

38 Rowley D A, Gutteridge J M C, Blake D R, Farr M, Halliwell B. Lipid peroxidation in rheumatoid arthritis. Thiobarbituric acid reactive material and catalytic iron salts in synovial fluid from rheumatoid patients. Clin Sci 1984; 66: 691-5.

39 Yoshikawa $\mathrm{T}$, Tanaka $\mathrm{H}$, Kondo $\mathrm{M}$. The increase of lipid peroxidation in rat adjuvant arthritis and its inhibition by superoxide dismutase. Biochem Med 1985; 33: 320-6.

40 Andrews F J, Blake D R, Freeman J, et al. Free radicals and reperfusion injury in the inflamed joint. In: Swaak A J G, Koster J F, eds. Free radicals and arthritic diseases. (Rijswijk: EURAGE, 1987: 167-78.

41 Lunec J, Brailsford S, Blake D R, Bacon P A. Self-perpetuating mechanisms of IgG aggregation in rheumatoid inflammation. J Clin Invest 1985; 76: 2084-90.

$42 \mathrm{McCord} \mathrm{J}$ M. Oxygen derived free radicals in post ischaemic tissue injury. $N$ Engl $J$ Med 1985; 312: 159-63.

43 Woodruff T, Blake D R, Freeman J, Andrews F J, Salt P, Lunec $\mathrm{J}$. Is chronic synovitis an example of reperfusion injury? Ann Rheum Dis 1986; 45: 608-11.

44 White B C, Krause G S, Aust S D, Eysler G E. Post ischaemic tissue injury by iron mediated free radical lipid peroxidation. Ann Emerg Med 1985; 14: 804-9.

45 Babbs C F. Role of iron ions in the genesis of reperfusion injury following successful cardiopulmonary resuscitation: preliminary data and a biochemical hypothesis. Ann Emerg Med 1985; 14: 777-83.

46 Berry H, Willoughby D A. Giroud J P. Evidence for an endogenous antigen in the adjuvant arthritic rat. $J$ Pathol 1973; 111: $229-38$. 